\title{
The Functions of the Collegiate Trainees' Committee
}

\author{
JAN SCOTT, Honorary Secretary, Collegiate Trainees Committee
}

The Royal College of Psychiatrists is the only Royal College which allows its trainees to take an active role in decision making and determining policy. Its origins can be dated from 1973 when, after pressure by the Association of Psychiatrists in Training, a Trainees' Working Party was formed. This was a sub-committee of the Education Committee and allowed for some input by trainees on matters specifically related to training. In 1979 , this working party was disbanded and replaced by the Collegiate Trainees' Committee ${ }^{1}$, which is a Special Committee of Council and is directly responsible to it. Since its inception, the CTC has gradually increased its representation within the College so that it now has at least one trainee on every committee of the College except the Court of Electors. We therefore have an opportunity to comment on all issues of relevance to trainees and to psychiatry as a whole.

The Committee consists of 36 elected trainees, four ex-officio members (the Dean and three Sub-Deans of the College), and two co-opted members (affiliate representatives on Council). Each Division of the College in England and Wales is represented by three trainees (of whom at least one is an Inceptor), whilst Scotland and Ireland are represented by six trainees each. The CTC meets at the time of the College Quarterly Meetings with an additional residential weekend meeting in September of each year. In the past, elections for CTC representatives have been held every two years. However, replacing the majority of members simultaneously was disruptive to the continuity of the work of the Committee. In an attempt to overcome this problem, the election of trainee representatives will be staggered so that half the CTC is re-elected in alternate years. In 1986 Inceptors and Senior Trainees in the Southern, Midland, East Anglian, Welsh, North West and Scottish Divisions will be asked to nominate and vote for their CTC representative, whilst the other Divisions will hold elections in 1987.

A recent audit of the activities of the Third CTC showed that it had made significant contributions on many issues of importance to trainee psychiatrists. In particular, they played an active role on the Working Party for the Review of the MRCPsych Examination and persuaded the College to drop questions about nationality and place of birth from the exam application forms. They expressed concern about the training implications of schemes including private hospital posts in their rotations and reported to the College on the GMC proposals on Basic Specialist Training. The Committee also advised the Central Approval Panel on the need for the trainee member of the approval visit team to be allowed to meet privately with trainees on such visits. Letters published in the Bulletin included requesting the College to encourage audit for its oducational value and expressing concern at the slow increase in consultant numbers and the 'bottle-neck' of applications for senior registrar posts. In addition they organised two Trainees' Forums on 'Psychiatric Tutors: Rumour or Reality' and 'Why Do Overseas Trainces Fail?, and set up two Working Parties in relation to these subjects. The CTC are presently involved in trying to persuade the relevant College committees to adopt the changes recommended in these areas. Like their predecessors, divisional representatives also organised Trainees' Days and helped arrange trainee representation on approval visits.

\section{The Fourth CTC}

The current CTC is keen to be representative of the views of all trainees in psychiatry. We would like more trainees to become Inceptors of the College so that they can participate in its activities. It is proposed that every Division will hold at least one Trainees' Day this year in an attempt to inform and discuss topics of concern to trainees (e.g. the new MRCPsych examination), and also to allow them the opportunity to make the CTC representatives aware of their opinions. Trainees' Days can be particularly useful for those in more 'isolated' training posts and can give trainees a chance to discuss problems which the divisional representative may be able to help deal with or can refer to the CTC.

In January 1986, as part of the College's Quarterly Meeting, there was a Trainees' Forum on 'Public Image of Psychiatry', a subject being reviewed by one of the three Working Parties that have been set up. The other topics under discussion are 'Part-time Training/Women in Psychiatry' and 'Consultant-Based Service'. The Convenors of each Working Party are Dinesh Bhugra (Psychiatry and the Media), Elaine Arnold (Part-time Training/Women in Psychiatry), and Rob Poole (Consultant-Based Service); trainees are encouraged to contact them at the College if they wish to offer information or their own views on any of these issues.

Any traince who does not know who their divisional representative is and wishes to contact them should consult the list published recently in the October 1985 issue of the Bulletin or write to the Secretary of the CTC at the Royal College of Psychiatrists.

Rerzrenct

'Waters, H. (1981) The Collegiate Trainees' Committec. Bulletin of the Royal College of Psychiatrists, 5, 69-70. 